\title{
EFFECTS OF REPLACEMENT OF METAKAOLIN WITH CEMENT ON THE MECHANICAL PROPERTIES OF SIFCON
}

\author{
Kailash Bhimraj Kumawat ${ }^{1}$, Akshay More ${ }^{2}$, Vikrant Netke ${ }^{3}$, Aakash Ashok Rikhe ${ }^{4}$ \\ ${ }^{1}$ Site Engineer at Shanti Constructions Nashik \\ ${ }^{2}$ Student of K.K.W college of engineering \\ ${ }^{3} B E$ CIVIL \\ ${ }^{4}$ Student of N.D.M.V.P College of engineering
}

\begin{abstract}
Slurry Infiltrated Fibrous CONcrete (SIFCON) is unique type of concrete invented by Lankard in 1979, containing high percentage of fiber about $6 \%$ to $20 \%$ by volume of concrete. SIFCON possesses high strength as well as large ductility and for excellent potential for structural application. Metakaolin $(M K)$ is a pozzolanic material, which improves the durabilityand strength of concrete. In this study the test programs were carried out with $2 \%, 3 \%$ and $4 \%$ of fiber content by volume of concrete with replacement of cement by Metakaolin at $5 \%$ and $7.5 \%$ by weight of cement. The aim of work is to optimize the percentage of fiber content and to minimize the cement usage by replacing it by Metakaolin. It also gives way to effective disposal of industrial waste to avoid global problem and protect environment. The main objective of this work was to determine the effect of replacement of cement with Metakaolin on mechanical property of SIFCON mortar. For that purpose compressive strength, flexural strength and Split tension strength of SIFCON specimen were tested after 7 and 28 days of curing, yielding positive results.

In this study, we found that $2 \%$ fiber replacement by volume of concrete and Metakaolin at $7.5 \%$ by weight of cement yields best and economical results.
\end{abstract}

Key Words: SIFCON, Metakaolin, Fiber,Control SIFCON(CS), and Pozzolanic.

\section{INTRODUCTION}

SIFCON is a high performance fibrous concrete having high fiber content infiltrated with either cement slurry or cement mortar and less than half a century old. Owing to the less time elapsed from its invention, very less research work has been performed to evaluate this concrete on grounds of durability and cost control. SIFCON possesses high toughness and impact resistance thus rendering it perfect for blast resistant, impact resistant structures alongside having good seismic retrofitting options. SIFCON is a concrete rich in cement matrix and fibrous content thus eliminating the coarse fraction. Elimination of coarser fraction and inclusion of large volume of fiber draws a rigid line between SIFCON and FRC.

The amount of fibers required in normal FRC is less than $2 \%$, whereas in SIFCON the volume of fibers ranges from $6 \%$ to $20 \%$. The large quantity of fiber and cement increase the overall production and placement cost of SIFCON, thus reducing its use.

In this work, the amount of fibers has been restricted to $2 \%$, $3 \%$ and $4 \%$ of volume of concrete. Furthermore, the quantity of cement has been partially replaced by Metakaolin (MK) obtained from industry. SIFCON specimens viz. compression, flexural, tension tests were prepared and evaluated for strength at 7 and 28 days of curing under normal temperature and conditions.

\section{LITERATURE SURVEY}

\subsection{Overview:}

When MK replaces cement, its significant increase in the compressive, flexural and split tensile strength was observed at early ages, so that the strength of concrete incorporate with MK was up to $30 \%$ greater than that of the ordinary concrete, depending mainly on replacement level of MK, $\mathrm{w} / \mathrm{c}$ ratio and testing age.

For this, non purified ground kaolin's obtained from different sources were thermally treated at a specified conditions. Two replacement levels $(5 \%, 7.5 \%)$ of Metakaolin were assigned for concrete production.

\section{MATERIALS AND METHODOLOGY}

Various types of materials used in making Slurry infiltrate fiber concrete (SIFCON) are discussed in the following table.

Table 1: Materials selected

\begin{tabular}{|c|c|}
\hline Materials & Type / size \\
\hline Cement & Ordinary Portland Cement (53 grade) \\
\hline Sand & Well graded sand. (River sand) \\
\hline Fiber & Hook ended steel fiber \\
\hline Metakaolin & 85C \\
\hline Water & Potable \\
\hline
\end{tabular}




\subsection{Fiber selected:}

In this experimental investigation hook end steel fibers are used.

- Fiber type : Hook Ended Steel Fiber

- $\quad$ Section type : Round

- Length : $35 \mathrm{~mm}$

- Diameter : $0.60 \mathrm{~mm}$

- Aspect ratio : 60

- Tensile strength : $1100 \mathrm{Mpa}$

- Density : $7.91 \mathrm{~g} / \mathrm{cc}$

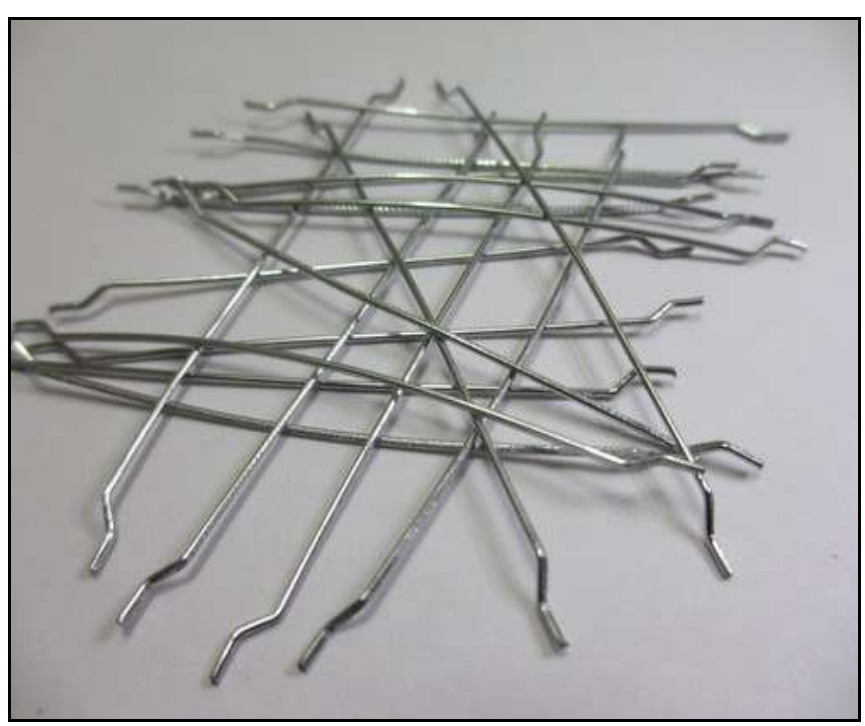

Figure 1: Hook end steel fiber

\subsection{Metakaolin:}

The Metakaolin used in this study is Metacam of grade $85 \mathrm{C}$. For this experimental work replacement of Metakaolin material is $5 \%$ and $7.5 \%$ by weight of cement were used in SIFCON. The HRM conforms to IS 456-2000.

\subsubsection{Proprties of Metakaolin:}

Metakaolin had $99.9 \%$ particles Blain $16 \mu \mathrm{m}$ with a mean particle size of about $3 \mu \mathrm{m}$.

Table 2: Physical properties of Metakaolin

\begin{tabular}{|c|c|}
\hline Property & Value \\
\hline Specific gravity & 2.516 \\
\hline Bulk Density $\left(\mathrm{g} / \mathrm{cm}^{3}\right)$ & $0.3-0.4$ \\
\hline GE Brightness & $79-82$ \\
\hline $\mathrm{D}_{10}$ & $<2.0 \mu \mathrm{m}$ \\
\hline $\mathrm{D}_{50}$ & $<4.5 \mu \mathrm{m}$ \\
\hline
\end{tabular}

\section{RESULTS}

The tests were conducted following the standard procedures and the results were obtained as follows:

\subsection{Compressive strength results for CS and MK:}

The test result for Control SIFCON on 7 and 28 days are displayed in the tabular as well as graphical form as given below:

Table 3: Overall compressive strength of CS 2\%F + MK5\%

\begin{tabular}{|c|c|c|c|c|}
\hline \multirow{2}{*}{$\begin{array}{c}\text { FIBER } \\
\%\end{array}$} & DAYS & \multicolumn{3}{|c|}{ COMPRESSIVE STRENGTH } \\
\cline { 3 - 5 } & & $5 \% \mathrm{MK}$ & $7.5 \% \mathrm{MK}$ & CONTROL \\
\hline $2 \%$ & 7 & 30.8 & 29.9 & 29.13 \\
& 28 & 34.7 & 47.2 & 32.53 \\
\cline { 2 - 5 } & & & & \\
\hline
\end{tabular}

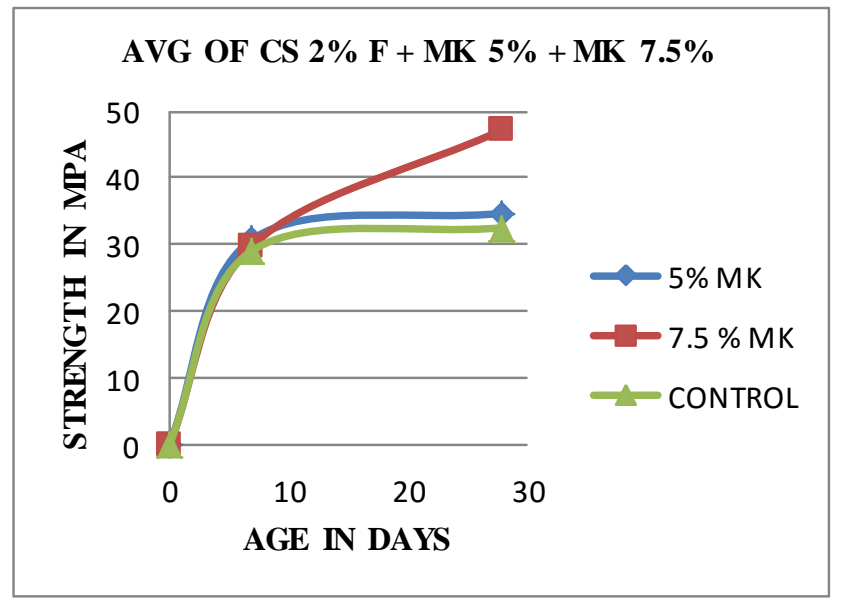

Graph 1: Avg compressive strength of CS 2\%F + MK5\% + MK7.5\%

\subsubsection{Study of graph:}

The graph indicates that the compressive strength at MK7.5\% is the highest strength than the MK5\% and control specimen. Hence the addition of Metakaolin increases the compressive strength of SIFCON. The percentage increased in compressive strength as compare to control SIFCON is $6.67 \%$ for MK5\% and $45.09 \%$ for MK7.5\%. The above graph shows that MK5\% and control specimen have flat curve which indicates that they had attained maximum strength, whereas the MK5\% shows inclined curve with further scope of increase in strength w.r.t. age in days.

Table 4: Overall compressive strength of CS 4\%F + MK5\% + MK7.5\%

\begin{tabular}{|c|c|c|c|c|}
\hline \multirow{2}{*}{$\begin{array}{c}\text { FIBER } \\
\end{array}$} & DAYS & \multicolumn{3}{|c|}{ COMPRESSIVE STRENGTH } \\
\cline { 3 - 5 } & & $5 \% \mathrm{MK}$ & $7.5 \% \mathrm{MK}$ & CONTROL \\
\hline $4 \%$ & 7 & 33.4 & 35.7 & 30.06 \\
& 28 & 55.5 & 59.7 & 51.4 \\
\cline { 2 - 5 } & & & & \\
\hline
\end{tabular}




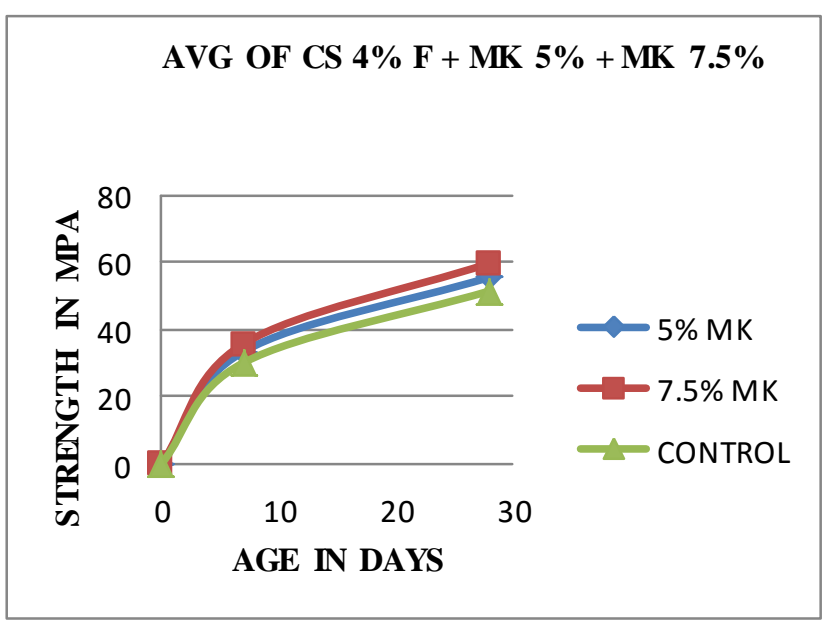

Graph 2: Avg compressive strength of CS 4\%F + MK5\% + MK7.5\%

\subsubsection{Study of graph:}

The graph indicates that the compressive strength at $7.5 \% \mathrm{MK}$ is the highest strength than the $5 \% \mathrm{MK}$ and control specimen. Hence the addition of Metakaolin increases the compressive strength of SIFCON. The percentage increased in compressive strength as compare to control SIFCON is $7.97 \%$ for MK5\% and $16.14 \%$ for MK7.5\%. The inclined curve indicates that the compressive strength may increase in further age in days.

\subsubsection{Crack pattern for Metakaolin blended SIFCON cube:}

A SIFCON cube blended with Meatakaolin undergoing compression test on a Compression Testing Machine (CTM) shows the following failure pattern. By visual inspection, crack pattern for MK cube was observed to be in a vertical zigzag manner and cup and cone type failure as seen in the figure below.

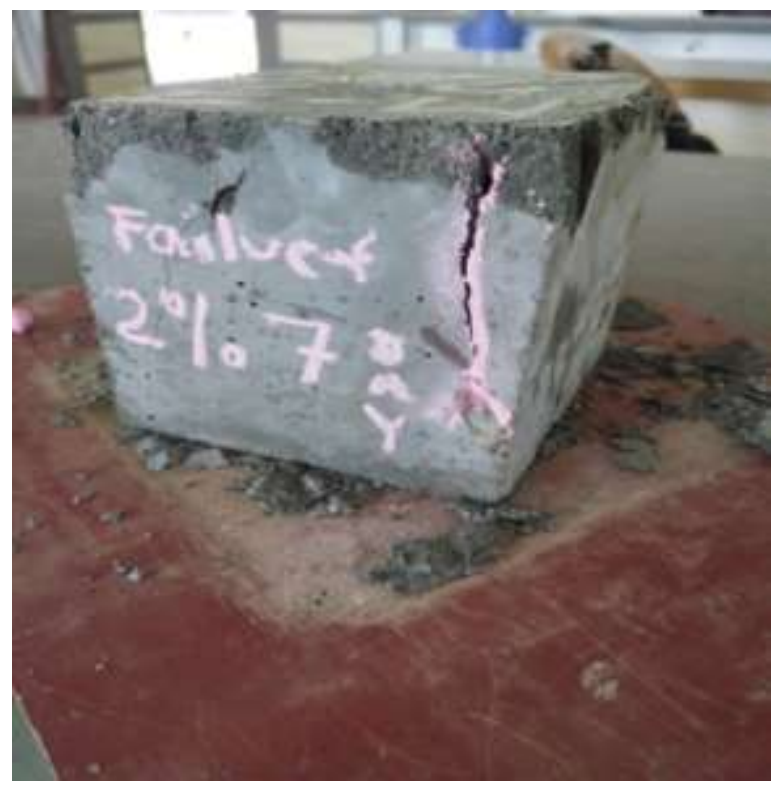

Figure 2: Crack pattern for Metakaolin blended SIFCON cube

\subsection{Flexure test strength results for $\mathrm{CS}$ and MK:}

The test result for Control SIFCON on 7 and 28 days are displayed in the tabular as well as graphical form as given below:

Table 5: Overall flexural strength of CS 2\%F + MK5\% +

\begin{tabular}{|c|c|c|c|c|}
\hline \multirow{2}{*}{ FIBER } & DAYS & \multicolumn{3}{|c|}{ FLEXURAL STRENGTH } \\
\cline { 3 - 5 }$\%$ & & $5 \% \mathrm{MK}$ & $7.5 \% \mathrm{MK}$ & CONTROL \\
\hline $2 \%$ & 7 & 10.27 & 13.33 & 8.33 \\
& & & & \\
\cline { 3 - 5 } & 28 & 12.6 & 15.5 & 9.13 \\
\hline
\end{tabular}

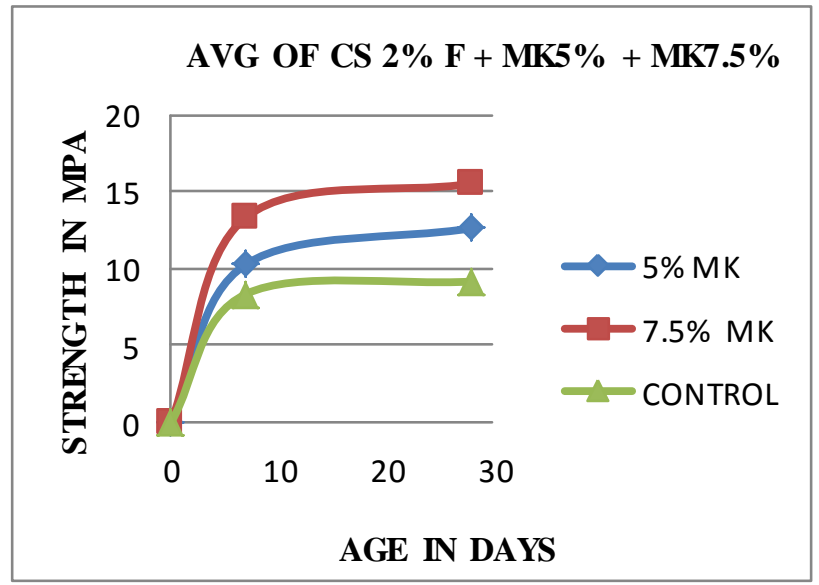

Graph 3: Avg flexural strength of CS $2 \% \mathrm{~F}+\mathrm{MK} 5 \%+$ MK7.5\%

\subsubsection{Study of graph:}

The graph indicates that the flexural strength at $7.5 \% \mathrm{MK}$ is the highest strength than the $5 \% \mathrm{MK}$ and control specimen. The percentage increased in flexural strength as compare to control SIFCON is 38\% for MK5\% and $69.76 \%$ for MK $7.5 \%$ Hence the addition of Metakaolin increases the flexural strength of SIFCON. The entire flat curves indicate the full attainment of strength.

Table 6: Overall flexural strength of CS 4\%F + MK5\% +

\begin{tabular}{|c|c|c|c|c|}
\hline \multirow{2}{*}{ FIBER } & DAYS & \multicolumn{3}{|c|}{ FLEXURAL STRENGTH } \\
\cline { 3 - 5 }$\%$ & & $5 \% \mathrm{MK}$ & $7.5 \% \mathrm{MK}$ & CONTROL \\
\hline $4 \%$ & 7 & 13.30 & 17.3 & 10.56 \\
\cline { 3 - 5 } & 28 & 17.20 & 22.45 & 11.88 \\
\hline
\end{tabular}




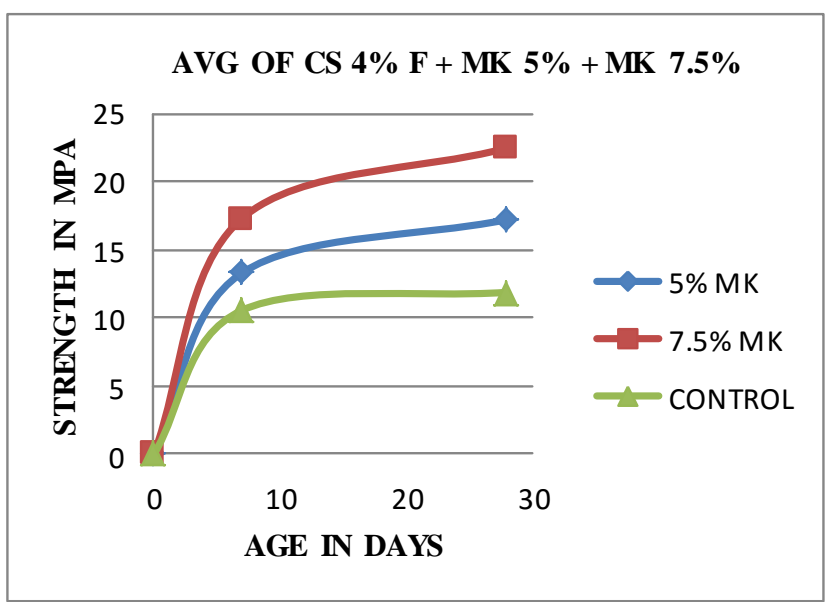

Graph 4: Avg flexural strength of CS 4\%F + MK 5\% + MK $7.5 \%$

\subsubsection{Study of graph:}

The graph indicates that the compressive strength at $7.5 \% \mathrm{MK}$ is the highest strength than the $5 \% \mathrm{MK}$ and control specimen. Hence the addition of Metakaolin increases the compressive strength of SIFCON. The percentage increased in flexural strength as compare to control SIFCON is 44.78\% for MK5\% and $88.97 \%$ for MK7.5\%. The graph shows the control specimen line as straight which means full attainment of strength; whereas the inclined curve of $5 \% \mathrm{MK}$ and $7.5 \% \mathrm{MK}$ indicates any further increment in strength w.r.t. age in days.

\subsubsection{Crack pattern for Metakaolin blended SIFCON beam:}

A SIFCON beam blended with Metakaolin undergoing flexural test on Universal Testing Machine (UTM) shows the following failure pattern. By visual inspection cracks were observed to be developed in the direction of the applied single point load.

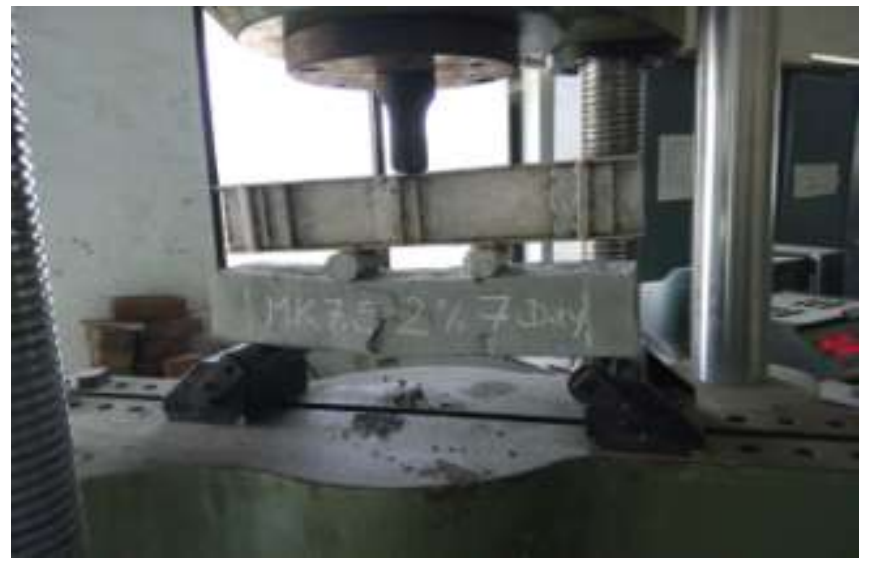

Figure 3: Crack pattern for Metakaolin blended SIFCON beam

\subsection{Split tensile test strength results for CS and} MK:

The test result for Control SIFCON on 7 and 28 days are displayed in the tabular as well as graphical form as given below:

Table 7: Overall split tensile strength of CS 2\%F + MK 5\%

\begin{tabular}{|c|c|c|c|c|}
\hline \multirow{2}{*}{$\begin{array}{c}\text { FIBER } \\
\%\end{array}$} & DAYS & \multicolumn{3}{|c|}{ SPLIT TENSION } \\
\cline { 3 - 5 } & & $5 \% \mathrm{MK}$ & $7.5 \% \mathrm{MK}$ & CONTROL \\
\hline $2 \%$ & 7 & 4.53 & 6.03 & 3.72 \\
& 28 & 7.02 & 7.82 & 5.74 \\
\cline { 2 - 5 } & 28 & & & \\
\hline
\end{tabular}

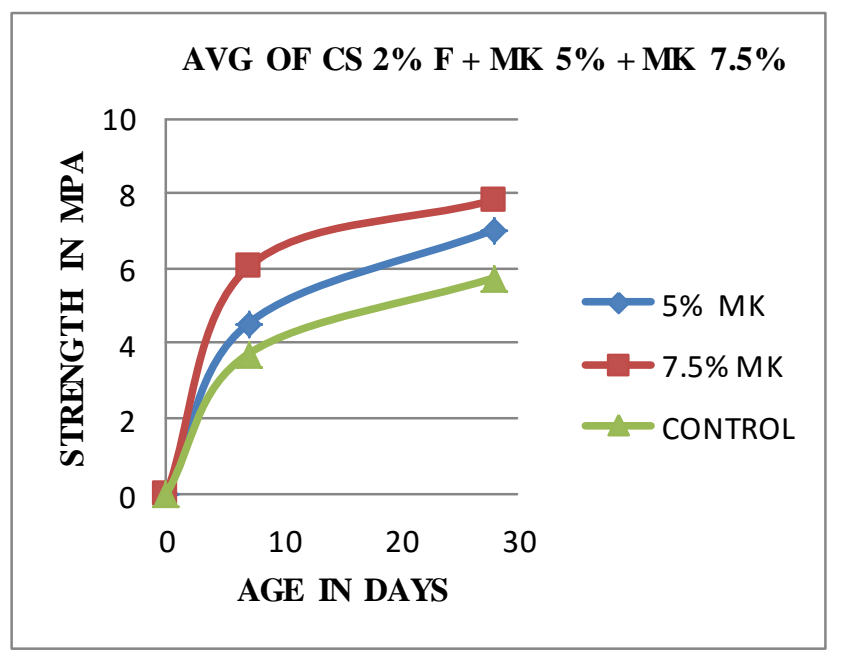

Graph 5: Avg split tensile strength of CS 2\%F + MK5\% + MK7.5\%

\subsubsection{Study of graph:}

The graph indicates that the strength at $7.5 \% \mathrm{MK}$ is the highest strength than the $5 \% \mathrm{MK}$ and control specimen. Hence the addition of Metakaolin increases the tensile strength of SIFCON. The percentage increased in tensile strength as compare to control SIFCON is $22.29 \%$ for MK5\% and $36.23 \%$ for MK7.5\%. The graph shows that addition of fiber and Metakaolin slightly increases the tensile strength of SIFCON.

Table 8: Overall split tensile strength of CS 4\%F + MK5\%

\begin{tabular}{|c|c|c|c|c|}
\multicolumn{2}{c|}{ FIBER } & DAYS & \multicolumn{3}{|c|}{ SPLIT TENSION } \\
\cline { 3 - 5 } & & $5 \% \mathrm{MK}$ & $7.5 \% \mathrm{MK}$ & $\begin{array}{c}\text { CONTRO } \\
\mathrm{L}\end{array}$ \\
\hline \multirow{2}{*}{$4 \%$} & 7 & 8.76 & 9.37 & 6.54 \\
& & & & 8.56 \\
\cline { 3 - 5 } & 28 & 9.89 & 9.96 & \\
\hline
\end{tabular}




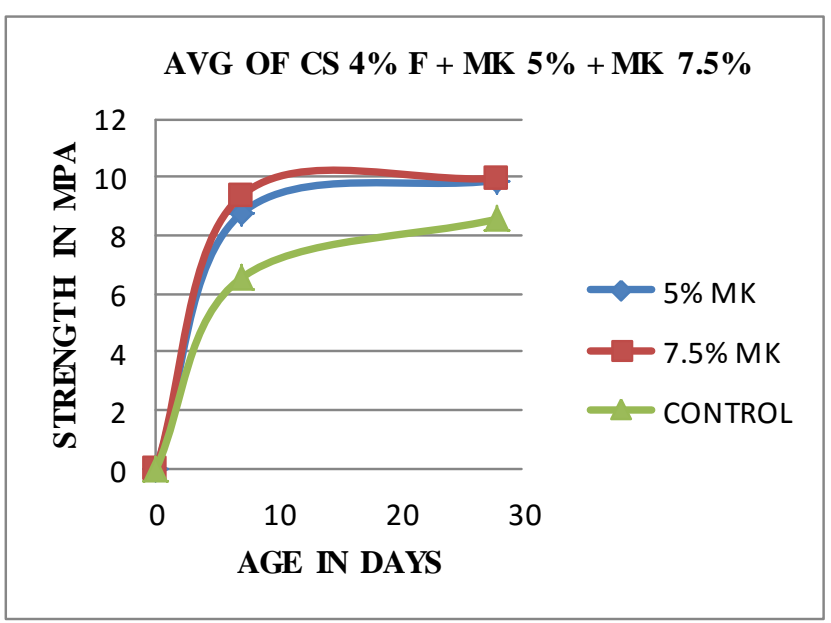

Graph 6: Avg split tensile strength of CS 4\%F + MK5\% + MK7.5\%

\subsubsection{Study of graph:}

The graph indicates that the strength at $7.5 \% \mathrm{MK}$ is almost near to $5 \% \mathrm{MK}$, but it is remarkably greater than the control specimen. The percentage increased in tensile strength as compare to control SIFCON is $15.53 \%$ for MK5\% and $16.35 \%$ for $\mathrm{MK} 7.5 \%$. The $7.5 \% \mathrm{MK}$ has achieved its maximum strength whereas the control and $5 \% \mathrm{MK}$ shows some further scope of increment in tensile strength of specimen w.r.t. age in days.

\subsubsection{Crack pattern for Metakaolin blended}

\section{SIFCON cylinder:}

A SIFCON cylinder blended with Metakaolin undergoing split tensile test on (CTM) machine shows following crack pattern. By visual inspection the cracks observed were along the length of cylinder as shown in fig below.

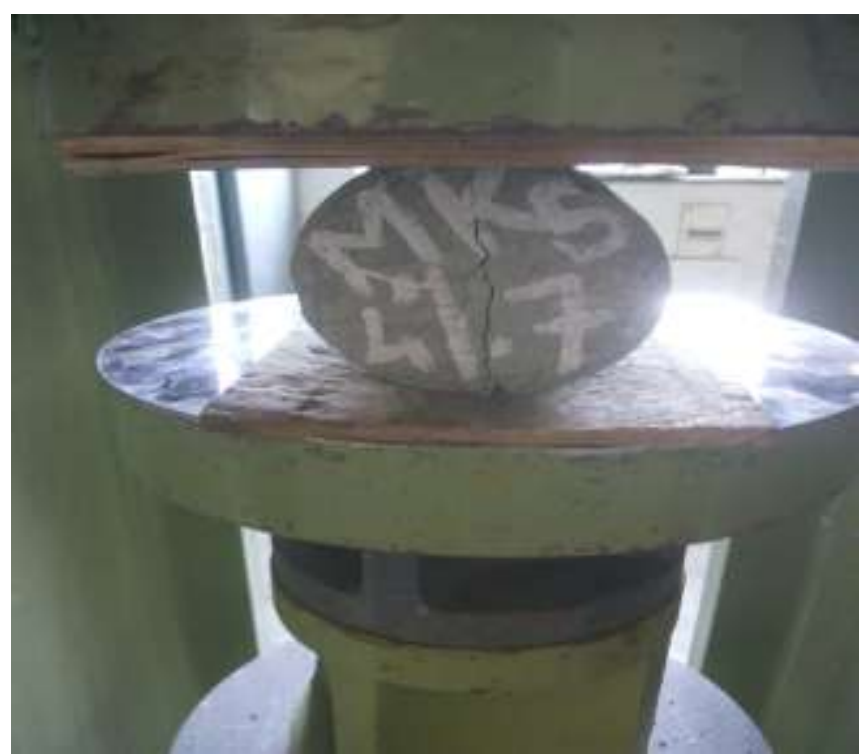

Figure 4: Crack pattern for metakaolin blended sifcon cylinder

\subsection{Cost analysis:}

Cost analysis is performed for three different stages involved in this project along with ULTRATECH OPC 53 grade cement i.e. for control SIFCON, metakaolin blended with control SIFCON(i.e. with $5 \% \mathrm{MK}$ ), metakaolin blended with control SIFCON(i.e. with $7.5 \% \mathrm{MK})$, Percentage of cement replaced by metakaolin is $5 \%$ and 7.5 $\%$ percent (by weight of concrete) steel fiber was added. The cost analysis for $1 \mathrm{~m}^{3}$ of concrete for the different stages is as follows:

Table 9: Cost analysis for CS + MK 5\%+ MK 7.5\%

\begin{tabular}{|c|c|c|c|}
\hline $\begin{array}{c}\% \text { of } \\
\text { Fiber }\end{array}$ & $\begin{array}{c}\text { Control } \\
\text { SIFCON }\end{array}$ & $\begin{array}{c}\text { Metakaolin } \\
5 \%\end{array}$ & $\begin{array}{c}\text { Metakaolin } \\
7.5 \%\end{array}$ \\
\hline $2 \%$ & 16735 & 17622 & 17993 \\
\hline $3 \%$ & 22121 & 23036 & 23432 \\
\hline $4 \%$ & 27513 & 28323 & 28862 \\
\hline
\end{tabular}

\section{Cost Analysis}

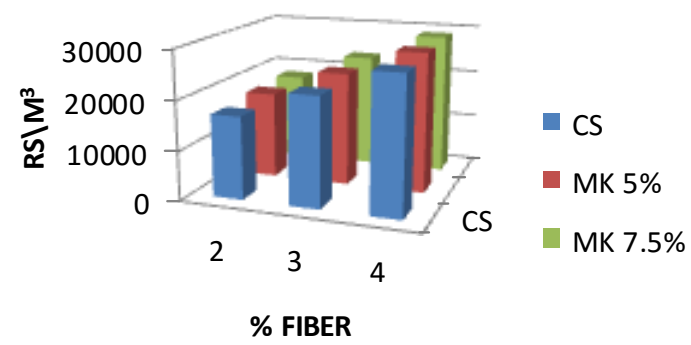

Graph 7: Cost analysis for CS + MK 5\%+ MK 7.5\%

\section{CONCLUSION}

1. Fiber addition results in more closely spaced cracks reducing the crack width and improved resistance to the cracks.

2. Due to high pozzolanic reaction of the Metakaolin and presence of crimped steel fibers in OPC, OPC has achieved significant improvement in its mechanical properties.

3. Compressive strength for $5 \% \mathrm{MK}$ is increased by $5 \%$ to $8 \%$, whereas for $7.5 \% \mathrm{MK}$ increment is seen by $8 \%$ to $45 \%$ with respect to control specimen containing fiber varying from $2 \%$ to $4 \%$.

4. Flexural strength for $5 \% \mathrm{MK}$ is increased by $25 \%$ to $45 \%$, whereas for $7.5 \% \mathrm{MK}$ increment is seen by $69 \%$ to $89 \%$ with respect to control specimen containing fiber varying from $2 \%$ to $4 \%$.

5. Split tensile strength for $5 \% \mathrm{MK}$ is increased by $15 \%$ to $22 \%$, whereas for $7.5 \% \mathrm{MK}$ increment is seen by $11 \%$ to $19 \%$ with respect to control specimen containing fiber varying from $2 \%$ to $4 \%$.

6. Difference in the cost of $1 \mathrm{~m}^{3}$ for casting of CS $2 \% \mathrm{~F}+$ $5 \% \mathrm{MK}$ and $\mathrm{CS} 4 \% \mathrm{~F}+5 \% \mathrm{MK}$ is $10,701 /$ - whereas difference in the compressive strength and impact 
strength for above combination is $1.3 \%,-4.28 \%$.Hence, from the above results, we can conclude that by increasing the fiber from $2 \%$ to $4 \%$ does not considerably improves the strength, therefore for use of $5 \% \mathrm{MK}, 2 \%$ of fiber replacement gives optimum and economical results.

7. Difference in the cost of $1 \mathrm{~m}^{3}$ for casting of CS $2 \% \mathrm{~F}+$ $7.5 \% \mathrm{MK}$ and $\mathrm{CS} 4 \% \mathrm{~F}+7.5 \% \mathrm{MK}$ is $10,869 /$ - whereas difference in the compressive strength and impact strength for above combination is $29.44 \%$, - $12.48 \%$ .Hence, from the above results, we can conclude that by increasing the fiber from $2 \%$ to $4 \%$ does not considerably improves the strength, therefore for use of $7.5 \% \mathrm{MK}, 2 \%$ of fiber replacement gives optimum and economical results.

8. Difference in the cost of $1 \mathrm{~m}^{3}$ for casting of CS $2 \% \mathrm{~F}+$ $5 \% \mathrm{MK}$ and $\mathrm{CS} 2 \% \mathrm{~F}+7.5 \% \mathrm{MK}$ is $371 /$ - whereas difference in the compressive strength and impact strength for above combination is $38.4 \%, 8.20 \%$.Hence, from the above results, we can conclude $\mathrm{CS} 2 \% \mathrm{~F}+$ $7.5 \% \mathrm{MK}$ considerably improves the strength, therefore $\mathrm{CS} 2 \% \mathrm{~F}+7.5 \% \mathrm{MK}$ gives optimum and economical results.

9. Use of Metakaolin above $7.5 \%$ and exact optimum use of fiber in SIFCON can be extended in further studies.

\section{REFERENCES}

[1] Antonio nanniet. "Properties of aramid-fiber reinforced concrete and SIFCON" Journal of materials in civil engineering ASCE-1992, pp 4:1-15

[2] Improving strength, drying shrinkage, and pore structure of concrete using metakaolin by Guneyisi and Gesoglu, Turkey (2007) Materials and Structures DOI 10.1617/s11527-007-9296-z

[3] Ding J, Li Z (2002) Effects of metakaolin and silica fume on properties of concrete. ACI Mater J 99(4):393-398. [4] Lankard D R. Slurry Infiltrated Fibre Concrete (SIFCON). Concrete International, Dec. 1984, pp. 44-47. 